\title{
An In Vivo Randomized Clinical Evaluation of the Surface Morphology of Nickel-Titanium, Beta-titanium, and Copper-Nickel-Titanium
}

\author{
Apoorva Sahu ${ }^{1}$, Veera Bhosale ${ }^{2}$, Dhananjay Ghunawat ${ }^{3}$, Pallavi Madanshetty ${ }^{4}$, Girish Rathi ${ }^{5}$, Mohammed YA Khan ${ }^{6}$
}

\begin{abstract}
Aim: Variation in the surface roughness of archwires not only leads to more accumulation of plaque but also modifies the coefficient of friction. This necessitated for the present study to evaluate the surface characteristics of $0.016 \times 0.022$-inch nickel-titanium, beta-titanium, and coppernickel-titanium archwires, before and after their use in the oral cavity using atomic force microscopy.

Materials and methods: The control and experimental samples were measured at three different positions under atomic force microscopy. The surface roughness was measured using roughness average, root mean square, and maximum height before and after use in the oral cavity among 60 adult participants. Data were analyzed using a one-way analysis of variance and Student's $t$ tests using the Statistical Package for Social Software (SPSS) v.20.0.

Results: The surface roughness of archwires increased considerably after their clinical use compared to controls for nickel-titanium $(p=0.013)$ and beta-titanium ( $p=0.002)$. A similar trend was noticed for root mean square where nickel-titanium $(p=0.014)$ and beta-titanium $(p=0.013)$ had increased root mean square. Maximum height was also noticed in nickel-titanium $(p=0.031)$ and beta-titanium $(p=0.016)$.

Conclusion: Surface roughness and the level of friction of the orthodontic wires increase significantly for nickel-titanium and beta-titanium after the clinical use. There is a difference in increase of surface roughness of the archwire within and between the bracket slots.

Clinical significance: Nickel-titanium and beta-titanium wires show more roughness and resultant higher friction levels after use in the oral cavity. Hence, care related to plaque accumulation is essential.

Keywords: Beta-titanium, Copper-titanium, Nickel-titanium, Orthodontics, Surface roughness.

The Journal of Contemporary Dental Practice (2020): 10.5005/jp-journals-10024-2818
\end{abstract}

\section{INTRODUCTION}

There has been a marked improvement in the field of mechanotherapy due to the availability of different alloys for orthodontic archwires. ' Orthodontic wires have to withstand thermal, chemical, and mechanical exposure in the patient's mouth. Several properties such as esthetics, weldability, resilience, spring back, formability, biostability, and friction have to be considered in the search for an ideal archwire. Along with these properties, surface roughness plays an important role in altering the property of the archwire. ${ }^{2}$ Furthermore, variation in the surface roughness not only leads to more accumulation of plaque $^{3}$ but also modifies the coefficient of friction. This increases with increase in the time period of contact with the teeth. Initially, the principal technique for determining surface roughness was surface profilometry. This technique was not authentic since it did not measure the defects along the surfaces. This led to the defects not being included in the final measurement. Furthermore, this technique was invasive in nature and it carried a risk of damaging the surface while the scanning process was being carried out. Noninvasive and nondestructive alternatives, based on optical methods like scanning tunneling microscopy, have been available for some time. The optical methods include ellipsometry, interferometry, speckle interferometry, and angular scattering distributions. Scanning probe microscopy includes atomic force microscopy (AFM) and magnetic force microscopy. Among these, AFM is the best option available as it appropriately provides the surface morphology and surface roughness in nanometers. The information obtained from AFM is always three-dimensional (3D). As stated by Yousif et al.,
${ }^{1}$ Private Practitioner, Pune, Maharashtra, India

${ }^{2}$ Department of Orthodontics and Dentofacial Orthopedics, Bharati Dental College and Hospital, Pune, Maharashtra, India

${ }^{3}$ Department of Conservative Dentistry and Endodontics, MA Rangoonwala College of Dental Sciences and Research Centre, Pune, Maharashtra, India

${ }^{4}$ Department of Prosthodontics, Rural Dental College, Pravara Institute of Medical Sciences, Loni, Maharashtra, India

${ }^{5}$ Department of Orthodonotics, Dr Rajesh Ramdasji Kambe Dental College, Akola, Maharashtra, India

${ }^{6}$ Department of Orthodontics, Saudi Italy Dental Polyclinic, Qariya-ulAluya Branch, Eastern Province, Dammam, Kindom of Saudi Arabia

Corresponding Author: Mohammed YA Khan, Department of Orthodontics, Saudi Italy Dental Polyclinic, Qariya-ul-Aluya Branch, Eastern Province, Dammam, Kindom of Saudi Arabia, Phone: +91 9966668308, e-mail: dryaserkhan@gmail.com

How to cite this article: Sahu P, Bhosale V, Ghunawat D, et al. An In Vivo Randomized Clinical Evaluation of the Surface Morphology of NickelTitanium, Beta-titanium, and Copper-Nickel-Titanium. J Contemp Dent Pract 2020;21(6):636-639.

Source of support: Nil

Conflict of interest: None

"The AFM provides a 3D profile on a nanoscale, by measuring forces between a sharp probe (radius $<10 \mathrm{~nm}$ ) and surface at very short distance $(0.2-10 \mathrm{~nm}$ probe-sample separation). The probe is 
supported on a flexible cantilever and the AFM tip gently touches the surface and records the small force between the probe and the surface." ${ }^{\prime 4}$ Previous in vitro studies done on orthodontic wires are irrelevant, as they fail to create the actual oral environment. The accumulation of plaque is the main factor, which distinguishes the oral cavity from in vitro media. ${ }^{5,6}$ This study was carried out to clinically evaluate the surface characteristics of $0.016 \times 0.022$-inch nickel-titanium (Ni-Ti), beta-titanium (B-Ti), and copper-nickeltitanium (Cu-Ni-Ti) archwires, before and after their use in the oral cavity for 30 days using AFM and test which wire provides the least risk factor for further plaque accumulation in patients.

\section{Materials and Methods}

The study was carried out in the clinical OPD of the dental institution in the department of orthodontics, Bharati Vidyapeeth Dental College, from July 2018 and July 2019. Ethical clearance was obtained from the institutional review board of Bharati Vidyapeeth Dental College (letter number BVDU 01, dated June 16, 2018). A written informed consent was obtained from all the participants. Materials used were $0.016^{\prime \prime} \times 0.022^{\prime \prime} \mathrm{Ni}-\mathrm{Ti}, \mathrm{B}-\mathrm{Ti}$, and $\mathrm{Cu}-\mathrm{Ni}-\mathrm{Ti}$ preformed archwires ( $G$ and $H$ Company), normal saline, Nanosurf Naio AFM, Eppendorf tube, elastomeric modules (American Orthodontics Company), and orthodontic pliers.

The inclusion criteria were as follows: individuals undergoing fixed orthodontic treatment using $0.018^{\prime \prime} \times 0.025^{\prime \prime}$ slot brackets with an MBT prescription, age between 18 years and 30 years, and exhibiting 1-1.5 mm crowding. The age of the participants should be above 18 years, without history of allergy to any of the materials being used and no previous history of any orthodontic procedure.

The exclusion criteria were as follows: individuals having a habit of chewing pan masala and tobacco, using mouthwashes, suffering from hyperacidity, or consuming aerated drinks and having known metal allergy.

All eligible participants were identified from January 2018 to June 2018. After the ethical clearance, those who agreed to participate and provide a written informed consent were only included in the study. The final sample size was therefore 120, even though we had identified 187 patients before the study was actually started.

The individuals participating in the study were divided into three groups (Table 1) using the lottery method. The control group (group I) consisted of 15 unused orthodontic wires ( 5 of Ni-Ti, 5 of $\mathrm{B}-\mathrm{Ti}$, and 5 of $\mathrm{Cu}-\mathrm{Ni}-\mathrm{Ti}$ ). The experimental group consisted of 30 wires (10 of $\mathrm{Ni}-\mathrm{Ti}, 10$ of $\mathrm{B}-\mathrm{Ti}$, and 10 of $\mathrm{Cu}-\mathrm{Ni}-\mathrm{Ti}$ ). The experimental group was further divided into two groups; the intrabracket

Table 1: Information on subject grouping

\begin{tabular}{|c|c|c|c|}
\hline Group & & Material used & $\begin{array}{l}\text { Number of } \\
\text { samples }\end{array}$ \\
\hline \multirow[t]{3}{*}{ Control } & Group I & $\mathrm{Ni}-\mathrm{Ti}$ & 5 \\
\hline & & $\mathrm{B}-\mathrm{Ti}$ & 5 \\
\hline & & $\mathrm{Cu}-\mathrm{Ni}-\mathrm{Ti}$ & 5 \\
\hline \multirow[t]{6}{*}{ Experimental } & Group II & $\mathrm{Ni}-\mathrm{Ti}$ & 10 \\
\hline & & $\mathrm{B}-\mathrm{Ti}$ & 10 \\
\hline & & $\mathrm{Cu}-\mathrm{Ni}-\mathrm{Ti}$ & 10 \\
\hline & Group III & $\mathrm{Ni}-\mathrm{Ti}$ & 10 \\
\hline & & $\mathrm{B}-\mathrm{Ti}$ & 10 \\
\hline & & $\mathrm{Cu}-\mathrm{Ni}-\mathrm{Ti}$ & 10 \\
\hline
\end{tabular}

experimental group (group II) in which the wire sample was within the bracket of the upper-left central incisor. The interbracket experimental group (group III) consisted of the wire sample being between the two central incisors brackets. The previous upper archwire was removed and the experimental archwire was carefully placed in the experimental area, ensuring that no part of it was touched either by hand or instruments and it was secured using elastic modules. After 30 days, the modules were removed. The study period was kept for 30 days as these wires are generally used as intermediate archwires. With the help of a thin-headed black permanent marker, the wire was marked at three areas: mesial and distal to the upper-left central incisor bracket and mesial to the upper-right central incisor bracket. After marking the points, the wire was carefully removed, cut at the specific points, and kept in the Eppendorf tube in normal saline. The wires were then studied under AFM; two-dimensional and three-dimensional images of the $\mathrm{Ni}-\mathrm{Ti}, \mathrm{B}-\mathrm{Ti}$ and $\mathrm{Cu}-\mathrm{Ni}$-Ti archwire surfaces were obtained using AFM. After the collection of data, master charts were prepared and were subjected to a statistical analysis. A one-way analysis of variance was done using post hoc Bonferroni's correction for multiple group comparisons using the Statistical Package for Social Software (SPSS) 20.0 (IBM Analytics, New York, USA). $p<0.05$ is considered statistically significant.

\section{Results}

A total of 90 participants participated in the study, while 30 of the participants did not complete the study due to personal reasons. Hence, the final data analysis was done for 60 subjects.

The surface roughness analysis showed that all three wires, i.e., $\mathrm{Ni}-\mathrm{Ti}, \mathrm{B}-\mathrm{Ti}$, and $\mathrm{Cu}-\mathrm{Ni}-\mathrm{Ti}$ had variations in the surface roughness for group I, group II, and group III; the data are noted in Table 2. The roughness average (RA) of $\mathrm{Ni}-\mathrm{Ti}$ was significantly higher in group III and group II compared to group I $(p=0.013)$; similar trend was observed for B-Ti wires ( $p=0.002)$, but no significant association between the group was noticed for the $\mathrm{Cu}$-Ni-Ti group ( $p=0.058$ ). Similar results were observed for root mean square (RMS) for $\mathrm{Ni}-\mathrm{Ti}$ and $\mathrm{B}-\mathrm{Ti}$, whereas a significant difference was observed between the groups ( $p=0.014$ and $p=0.013$ ), but there were no significant differences in the $\mathrm{Cu}-\mathrm{Ni}-\mathrm{Ti}$ group $(p=0.069)$. The maximum height was significantly higher in group III and group II compared to group I for $\mathrm{Ni}-\mathrm{Ti}$ and $\mathrm{B}-\mathrm{Ti}(p=0.031$ and 0.016$))$, whereas no significant difference between group III and group II was noticed ( $p=0.108$ ).

\section{Discussion}

The present study was conducted to evaluate the changes in surface roughness of three routinely used orthodontic wires, i.e., $\mathrm{Ni}-\mathrm{Ti}, \mathrm{B}-\mathrm{Ti}$, and $\mathrm{Cu}-\mathrm{Ni}-\mathrm{Ti}$ before and after their use in the oral cavity for 30 days. There are many studies evaluating the surface roughness of wires either in vitro or in vivo. None of the studies have tried to evaluate the changes in surface roughness of the orthodontic wire within the bracket slot and between two brackets. There are different factors, which affect surface roughness of the archwire within the bracket slot area. First-order, second-order, third-order bends, which are inbuilt in the bracket can cause friction in-between the bracket and the wire, which increases the roughness of the wire. During mastication, the trampoline effect generated between the edge of the bracket and the wire also affects the surface roughness of the wire. Modules used to secure the wire in the brackets retain saliva causing corrosion of 
Table 2: Comparison of roughness average (RA), root mean square (RMS) and maximum of height (MH) for each studied groups

\begin{tabular}{|c|c|c|c|c|}
\hline \multirow[b]{3}{*}{ Morphology } & \multirow[b]{2}{*}{ Control mean $(\mathrm{nm})$} & \multicolumn{2}{|c|}{ Experimental mean $(\mathrm{nm})$} & \multirow[b]{3}{*}{$p$ value } \\
\hline & & Intrabracket & Interbracket & \\
\hline & Group I & Group II & Group III & \\
\hline \multicolumn{5}{|l|}{ RA } \\
\hline $\mathrm{Ni}-\mathrm{Ti}$ & $66.71 \pm 5.32$ & $204.13 \pm 94.56$ & $149.42 \pm 122.12$ & 0.013 \\
\hline B-Ti & $106.93 \pm 13.19$ & $224.41 \pm 83.23$ & $145.31 \pm 39.83$ & 0.002 \\
\hline $\mathrm{Cu}-\mathrm{Ni}-\mathrm{Ti}$ & $157.74 \pm 23.21$ & $237.64 \pm 122.74$ & $221.46 \pm 97.31$ & 0.058 \\
\hline \multicolumn{5}{|l|}{ RMS } \\
\hline $\mathrm{Ni}-\mathrm{Ti}$ & $88.34 \pm 10.63$ & $283.81 \pm 141.33$ & $202.71 \pm 159.43$ & 0.014 \\
\hline $\mathrm{B}-\mathrm{Ti}$ & $146.94 \pm 28.32$ & $302.24 \pm 113.46$ & $183.26 \pm 45.58$ & 0.013 \\
\hline $\mathrm{Cu}-\mathrm{Ni}-\mathrm{Ti}$ & $200.42 \pm 25.20$ & $299.13 \pm 148.00$ & $283.28 \pm 120.32$ & 0.069 \\
\hline \multicolumn{5}{|l|}{$\mathrm{MH}$} \\
\hline $\mathrm{Ni}-\mathrm{Ti}$ & $402.21 \pm 129.00$ & $1019.06 \pm 496.78$ & $806.25 \pm 622.18$ & 0.031 \\
\hline B-Ti & $583.8 \pm 119.72$ & $1317.80 \pm 680.84$ & $601.31 \pm 168.75$ & 0.016 \\
\hline $\mathrm{Cu}-\mathrm{Ni}-\mathrm{Ti}$ & $691.24 \pm 106.44$ & $880.38 \pm 551.14$ & $1033.04 \pm 382.10$ & 0.108 \\
\hline
\end{tabular}

the wire, which will affect the surface roughness of the archwire. So, there is a need to study the changes in surface morphology of the archwire within the bracket slot and the archwire between two adjacent brackets. In the present study, AFM was used to evaluate the surface roughness since it is noninvasive and provides a 3D result of the impressions that seem to be realistic in nature. ${ }^{4}$ For $\mathrm{Ni}-\mathrm{Ti}$ wires, the surface roughness increased two times between group I and group III and three times between group I and group II. This shows that the increase in surface roughness between groups II and III is almost twice, which was not noted in any other previous studies. ${ }^{4-9}$ For B-Ti wires, RA and RMS increased approximately two times between group I and group II and approximately one and a half times between group I and group III. The peak in surface roughness, i.e., maximum height $(\mathrm{MH})$ increase, was approximately two and a half times between group I and group II and minimal change between groups I and III. Rongo et al. ${ }^{6}$ analyzed the results of aging on the esthetics of $\mathrm{Ni}-\mathrm{Ti}$ wires using AFM where they reported of an increase in RA, RMS, MH values between control and experimental groups, similar to that of our findings. Another study by Suarez et al. ${ }^{8}$ reported that the mean RMS of the $\mathrm{Ni}-\mathrm{Ti}$ archwires group increased after immersing it in saline solution for 30 days. However, our study showed that the mean RMS value of $\mathrm{Ni}$-Ti for group I was $0.0883 \mu \mathrm{m}$, which was increased to 0.283 $\mu \mathrm{m}$ in group II and $0.202 \mu \mathrm{m}$ in group III. This difference in RMS values of $\mathrm{Ni}-\mathrm{Ti}$ archwires in the control group, between their study and our present study, can be because of archwires used from different manufacturers. A study by D'Anto et al. ${ }^{2}$ evaluated the surface roughness values of as received $\mathrm{Ni}-\mathrm{Ti}$ archwires via AFM and found that RA, RMS, and MH values for Sentalloy Ni-Ti wires were comparable to values of our study. Another study by Bourauel et al. $^{3}$ evaluated the surface roughness of commercially available $\mathrm{Ni}-\mathrm{Ti}$ by using AFM and specular reflectance; they concluded that surface roughness of $\mathrm{Ni}-\mathrm{Ti}$ wires ranged from 0.10 to $1.30 \mu \mathrm{m}$. The readings obtained in the present study for the mean surface roughness of $\mathrm{Ni}-\mathrm{Ti}$ archwires were $66.71 \pm 5.32 \mathrm{~nm}(0.066 \mu \mathrm{m})$. The difference in surface roughness values of $\mathrm{Ni}-\mathrm{Ti}$ archwires in the control group can be because the archwires used are from different manufacturers; also only one wire was evaluated to check the surface roughness. In another study by Yu et al., ${ }^{9}$ surface roughness of the $\mathrm{Ni}-\mathrm{Ti}$ archwire was evaluated using a surface profilometer and they found higher readings as compared to our study. This can be because they have used surface profilometry as a tool to study surface roughness, which uses a fine stylus to scan the topography in a single line of a preselected area. But the main drawback of this method was the impossibility of measuring surface defects adjacent to the scan line. Furthermore, the profilometry was invasive, and damage to the surface was possible during scanning. The basic difference between noninvasive techniques (AFM) and profilometry is that AFM uses a certain region of the wire surface and profilometry uses a single line to determine the surface properties. ${ }^{3}$ Anto et al. ${ }^{2}$ calculated surface roughness values of as received $\mathrm{B}-\mathrm{Ti}$ archwires via AFM higher than our study findings. Bourauel et al. ${ }^{3}$ evaluated the surface roughness of one commercially available B-Ti archwires using AFM, profilometry, and specular reflectance. Approximately, the surface roughness was $0.21 \mu \mathrm{m}$. Surface roughness for the B-Ti wire in the present study was $0.10 \mu \mathrm{m}$. This difference in surface roughness values of $\mathrm{B}-\mathrm{Ti}$ archwires in the control group can be because of archwires used from different manufacturers; also only one wire was evaluated to check the surface roughness in their study.

In another study by Yu et al., ${ }^{9}$ the surface roughness of the B-Ti archwire was evaluated using a surface profilometer and they found surface roughness of the B-Ti archwire to be higher as compared to present study readings. This difference can be because they have evaluated the surface roughness by surface profilometry, which may not be always an accurate tool for measurement. Juvvadi et al. ${ }^{10}$ also evaluated surface roughness of B-Ti (TMA) wires with a surface profilometer. Their results showed surface roughness of TMA as $0.23 \mu \mathrm{m}$ as compared to $0.10 \mu \mathrm{m}$ of the present study. So, it can be observed that the surface roughness of the B-Ti wire is more when evaluated by surface profilometry. It can also be because the wires used in both studies are from different manufacturers. Suarez et al. ${ }^{8}$ carried out an in vitro evaluation of surface topographic of $\mathrm{Cu}-\mathrm{Ni}-\mathrm{Ti}$ by AFM. The mean RMS values in their study increased after immersing it in saline solution for 30 days. In the present study, the RMS mean value of $\mathrm{Cu}-\mathrm{Ni}-\mathrm{Ti}$ for group I was $0.200 \mu \mathrm{m}$, which increases to $0.299 \mu \mathrm{m}$ in group II and $0.283 \mu \mathrm{m}$ in group III. These differences in RMS value of $\mathrm{Cu}-\mathrm{Ni}-\mathrm{Ti}$ archwires in the control group 
can be because the archwires used are from different manufacturers. Their study values cannot be directly compared with RMS values of group II and group III in this case, since our study is an in vivo study and their study was an in vitro study. In another study by Yousif et al., ${ }^{4}$ the least surface roughness post use was seen with the stainless steel wire. $\mathrm{Cu}-\mathrm{Ni}-\mathrm{Ti}$ wires had the roughest surface $(499 \mu \mathrm{m})$. This was different than our present study findings. $\mathrm{Ni}$-Ti wires showed a surface roughness of $313.8 \mu \mathrm{m}$ after use while for TMA wires it was $221.2 \mu \mathrm{m}$. These findings were much different than the present study findings. This could be due to the amount of time spent in the mouth, eating pattern, material make and company, etc. ${ }^{11,12}$

Sliding biomechanics, when fused with fixed appliances, develop frictional forces with the bracket and wire interaction. A high frictional force can always affect the treatment outcome also. Hence, the frictional forces should be kept minimal for an optimal response to tooth movement. Factors such as hardness of the wire, its roughness, and its topography all affect the mechanism and the resultant surface roughness. ${ }^{13,14}$

The overall study results showed that increase in surface roughness was present in the mouth with all the wires and least with $\mathrm{Ni}-\mathrm{Ti}$. Hence, further studies with $\mathrm{Ni}-\mathrm{Ti}$ and in cases with more induction of acidic agents like beverages are needed to stimulate an actual environment. This can provide more evidence to use of $\mathrm{Ni}-\mathrm{Ti}$ as a better option for orthodontic treatment. ${ }^{15}$ Further regression analyzes are needed to evaluate the cutoff time where the wires actually start undergoing major changes in the oral cavity and contribute to surface roughness and resultant plaque accumulation.

\section{Conclusion}

The RA, RMS, and $\mathrm{MH}$ values of $\mathrm{Ni}-\mathrm{Ti}$ and $\mathrm{B}-\mathrm{Ti}$ between the three groups were significantly different, which indicates that the surface roughness and peak in the surface roughness increase in-between these three groups. There is a marked difference in surface roughness of archwires in-between the bracket and within two brackets. Further studies in larger cohort samples are necessary to confer our result.

\section{References}

1. Eliades T. Orthodontic materials research and applications: part 2. Current status and projected future developments in materials and biocompatibility. Am J Orthod Dentofacial Orthop 2007;131(2): 253-262. DOI: 10.1016/j.ajodo.2005.12.029.
2. D'Anto V, Roberto R, Gianluca A, et al. Evaluation of surface roughness of orthodontic wires by means of atomic force microscopy. Angle Orthod 2012;82(5):922-928. DOI: 10.2319/100211-620.1.

3. Bourauel C, Fries T, Drescher D, et al. Surface roughness of orthodontic wires via atomic force microscopy, laser specular reflectance, and profilometry. Eur J Orthod 1998;20(1):79-92. DOI: 10.1093/ejo/ 20.1.79.

4. Yousif AA, Abd El-Karim UM. Microscopic study of surface roughness of four orthodontic arch wires. Tanta Dent J 2016;13(4):199-207. DOI: 10.4103/1687-8574.195714.

5. Krishnan V, Kumar J. Mechanical properties and surface characteristics of three archwire alloys. Angle Orthod 2004;74(6):825-831. DOI: 10.1043/0003-3219(2004)0742.0.CO;2.

6. Rongo R, Ametrano G, Gloria A, et al. Effects of intraoral aging on surface properties of coated nickel-titanium archwires. Angle Orthod 2014;84(4):665-672. DOI: 10.2319/081213-593.1.

7. Eliades T, Bourauel C. Intraoral aging of orthodontic materials: the picture we miss and its clinical relevance. Am J Orthod Dentofacial Orthop 2005;127(4):403-412. DOI: 10.1016/j.ajodo.2004. 09.015 .

8. Suarez C, Vilar T, Gil J, et al. In vitro evaluation of surface topographic changes and nickel release of lingual orthodontic archwires. J Mater Sci: Mater Med 2010;21(2):675-683. DOI: 10.1007/s10856-0093898-7.

9. $\mathrm{Yu} \mathrm{JH}, \mathrm{Wu} \mathrm{LC}, \mathrm{Hsu} J \mathrm{JT}$, et al. Surface roughness and topography of four commonly used types of orthodontic archwire. J Med Biol Eng 2011;31(5):367-370. DOI: 10.5405/jmbe.700.

10. Juvvadi SR, Kailasam V, Padmanabhan S, et al. Physical, mechanical, and flexural properties of 3 orthodontic wires: an in-vitro study. Am J Orthod Dentofacial Orthop 2010;138(5):623-630. DOI: 10.1016/ j.ajodo.2009.01.032.

11. Lee GJ, Park KH, Park YG, et al. A quantitative AFM analysis of nanoscale surface roughness in various orthodontic brackets. Micron 2010;41(7):775-782. DOI: 10.1016/j.micron.2010.05.013.

12. Lee TH, Park KH, Jeon JY, et al. Changes in surface roughness of bracket and wire after experimental sliding - preliminary study using an atomic force microscopy. Korean J Orthod 2010;40(3):156-166. DOI: 10.4041/kjod.2010.40.3.156.

13. Doshi UH, Bhad-Patil WA. Static frictional force and surface roughness of various bracket and wire combinations. Am J Orthod Dentofacial Orthop 2011;139(1):74-79. DOI: 10.1016/j.ajodo.2009.02.031.

14. Choi S, Eun-Young H, Hun-Kuk P, et al. Correlation between frictional force and surface roughness of orthodontic archwires. Scanning 2015;37(6):399-405. DOI: 10.1002/sca.21225.

15. Husain N, Kumar A. Frictional resistance between orthodontic brackets and archwire: an in vitro study. J Contemp Dent Pract 2011;12(2):91-99. DOI: 10.5005/jp-journals-10024-1015. 